\title{
Mobile website characteristics of leading tobacco product brands: cigarettes, smokeless tobacco, e-cigarettes, hookah and cigars
}

\author{
Erin Keely O'Brien, ${ }^{1}$ Mario Antonio Navarro, ${ }^{2}$ Leah Hoffman ${ }^{2}$
}

\begin{abstract}
1 Office of Science, Food and Drug Administration Center for Tobacco Products, Silver Spring, Maryland, USA

${ }^{2}$ Office of Health

Communication and Education, Food and Drug Administration Center for Tobacco Products, Silver Spring, Maryland, USA
\end{abstract}

\section{Correspondence to}

Dr. Erin Keely O'Brien, Office

of Science, Center for Tobacco

Products, U.S. Food and Drug

Administration, Silver Spring,

MD 20993, USA;

erin.obrien@fda.hhs.gov

Received 5 June 2018

Revised 8 August 2018

Accepted 9 August 2018

Published Online First

30 August 2018

\section{ABSTRACT}

Significance Most US adults use smartphones for internet access. Understanding what they see when they view smartphone-optimised (mobile) tobacco websites is important, as it can inform tobacco education and cessation strategies. This study describes mobile tobacco websites for leading brands of cigarettes, cigars, smokeless tobacco (smokeless), e-cigarettes and hookah. Methods We identified 130 leading tobacco brands based on sales, advertising spending and self-report data. Of these, 62 brands had mobile websites. We conducted an inductive content analysis (ie, where we derived the coding scheme from what we observed) of website characteristics by dual-coding: age requirements, warning display, brand engagement methods (eg, social features) and sales strategies (eg, coupons).

Results All cigarette and most smokeless websites required age-verified accounts for entry, while $76 \%$ of e-cigarette websites required accounts only for making purchases. All cigarette and smokeless websites showed warnings, but a minority of e-cigarette and cigar websites did, and no hookah websites did. Many websites required users to scroll up to view warnings. Most e-cigarette websites, most hookah websites, and half of cigar websites linked to multiple social media platforms; however, most cigarette and smokeless websites facilitated socialisation internally. All cigarette, most smokeless and no hookah websites offered coupons. Many cigarette and smokeless coupons were time-sensitive and location-based.

Conclusions We highlight issues in how tobacco brand websites address youth access, display warnings, engage consumers and facilitate purchase. Results can help public health educators and practitioners better understand tobacco marketing as a context for designing tobacco interventions.

\section{INTRODUCTION}

Between 2014 and 2015, cigarette company website spending increased by $\$ 11$ million, ${ }^{1}$ and smokeless tobacco company website spending increased by $\$ 2$ million. $^{2}$ Furthermore, smartphone ownership has drastically increased among US adults, from $56 \%$ in 2013 to $88 \%$ in $2017 . .^{3}, 4$ People now use smartphones more than computers to access the internet. $^{5}$ Several tobacco-susceptible populations ${ }^{6}$ are particularly reliant on smartphones: $98 \%$ of young adults own smartphones, ${ }^{4}$ sexual minorities are more likely to own smartphones than their straight counterparts ${ }^{7}$ and low-income adults are more likely to access the internet exclusively with a smartphone. ${ }^{8}$ Additionally, $64 \%$ of adult smokers, ${ }^{9}$
$88 \%$ of young adult smokers, ${ }^{9} 88 \%$ of youth, ${ }^{10}$ and $64 \%$ of low-income adults own smartphones. ${ }^{8}$ Given the increase in tobacco industry website spending and the increase in smartphone-based internet use by several tobacco-susceptible populations, it is important to understand the content of smartphone-optimised (mobile) tobacco brand websites (ie, often simplified versions of full websites designed to be viewed on small smartphone screens). ${ }^{11} 12$ The current study describes four main features of mobile websites: age restrictions, warning label displays, brand engagement methods and purchase facilitation strategies. Since past research has not studied smartphone-optimised tobacco brand websites, we reviewed literature on tobacco websites in general.

Restricting youth access to websites of tobacco brands (brand websites) is important, as youth who engage with online tobacco marketing are more likely to initiate tobacco use, increase use frequency, progress to polytobacco product use and continue use. ${ }^{1314}$ One potentially effective strategy to prevent youth access is to require all users to register for an account and verify their age using third-party services. A less effective (ie, easier to falsify) method is to require users to click a button on a pop-up window to affirm they are of age (click-through verification). ${ }^{15}$ Studies on restricting youth access to tobacco websites indicate room for improvement. ${ }^{15-19}$ Studies of e-cigarette brand ${ }^{16} 19$ and vendor ${ }^{151718}$ websites find that some have no age restrictions, very few require registration and most have click-through verification. ${ }^{19}$ Only one study has assessed age verification for websites for products besides e-cigarettes. This study assessed 12 total cigarette, cigar and smokeless tobacco websites and found that most required registering for an account.

Warnings regarding the health effects of tobacco use can serve as a source of health information, discourage initiation and promote cessation. ${ }^{20}$ Several federal laws require warnings to be displayed on packaging and advertising for tobacco products sold or distributed in the USA. 21-26 Warning requirements are currently in effect for cigarettes and smokeless tobacco products. ${ }^{21-24}$ As of 10 August 2018, tobacco products including e-cigarettes and hookah must follow warning requirements. ${ }^{25} 26$ Although the law also requires warnings for cigars (and pipe tobacco), ${ }^{25}$ the US District Court for the District of Columbia issued an order enjoining Food and Drug Administration (FDA) from enforcing this requirement for these products until after a related court case is settled. ${ }^{27}$ 
Little research has described how warnings are currently displayed on tobacco brand websites. One study assessing 57 e-cigarette vendor websites (including some brand websites) found that more than two-thirds displayed some type of health warning, although they were usually difficult to see. ${ }^{18}$ Similar research on other product types is limited.

Companies selling consumer goods foster brand loyalty and promote purchase by building brand engagement (ie, the process of forming a psychological attachment with a brand). ${ }^{28-30}$ Studies show that tobacco companies provide diverse online engagement opportunities ('touchpoints') for tobacco users and potential users, including interactive brand websites, digital ads, emails, videos, online sweepstakes and social media. ${ }^{191-36}$ Each brand touchpoint can drive traffic to others, for example, between tobacco brand websites, retail websites and branded content on social media platforms such as Facebook, Instagram, Twitter and YouTube. ${ }^{1937}$ Tobacco companies email consumers in their databases as often as nine times each month to drive traffic to the brand website through coupons, games, social activities/events and sweepstakes or contests. ${ }^{3038} 39$

Purchase facilitation strategies differ between products sold in-store and those sold online. Many e-cigarette ${ }^{15}$ and hookah ${ }^{40}$ websites sell products online. Although research describing online tobacco sales strategies is lacking, one study found e-cigarette brands use various online price promotions to facilitate purchase. ${ }^{41}$ Studies show certain web strategies can increase online purchases, such as live chat, ${ }^{42}$ free shipping ${ }^{43}$ and consumer reviews or recommendations. ${ }^{44}$ Tobacco companies not selling products online have long used coupons to facilitate in-store purchase using digital and mail coupons. ${ }^{19} 3437384546$ The use of coupons is widespread-one study found that $40 \%$ of adult smokers had used a coupon to buy cigarettes in the past year. ${ }^{47}$ Some tobacco brands offer time-sensitive mobile coupons which are delivered to smartphones and must be used within 5 minutes of store entry. ${ }^{48}$ This is consistent with recommendations from mobile coupon marketing research. ${ }^{49} 50$ Other consumer product websites often feature store locators ${ }^{51}$; one study identified a store locator that could identify where to buy a specific cigarette brand variety. ${ }^{52}$

\section{Current study}

To our knowledge, no studies have examined mobile tobacco websites, and only one small study $(\mathrm{n}=12)$ described websites for multiple types of tobacco products. ${ }^{19}$ Investigating mobile tobacco website characteristics is important because smartphones are the most commonly used technology for internet access, ${ }^{5}$ and mobile websites are often simplified versions of websites accessed by computers. ${ }^{11}{ }^{12}$ Furthermore, describing characteristics of mobile websites for multiple product types is important, as this information can inform targeted interventions for a variety of tobacco products. The current study describes age restrictions, warning displays, brand engagement strategies and purchase facilitation strategies for mobile websites for leading brands of cigarettes, smokeless tobacco, e-cigarettes, hookah and cigars.

\section{METHODS}

\section{Search strategy}

We identified leading brands of five tobacco product types (cigarettes, cigar products, e-cigarettes, smokeless tobacco and hookah) using three data sources. We started with the top 20 brands in five product categories (cigarette, smokeless tobacco, e-cigarette, hookah, cigar), based on 2016 dollar sales from
Nielsen Scantrack data for total US convenience stores and all outlets combined. For e-cigarettes, we collectively considered top brands in Nielsen's eight categories (electronic cigarette disposable, electronic cigarettes kits, electronic cigarettes refills liquid, electronic cigarettes refills non-liquid, electronic cigars disposable, electronic hookahs disposable, electronic hookahs refills liquid and electronic pipes kits). We considered Nielsen's three cigar categories separately (cigars, cigarillos, other cigars). As each cigar brand sold more than one type of cigar, we collapsed these categories. Dropping duplicative sub-brands (eg, Marlboro 100's) yielded 18 cigarette, 20 e-cigarette, 20 smokeless tobacco and 41 cigar brands. Nielsen Scantrack data only contained one hookah brand (Sultan). Next, we identified brands in Kantar's online advertising expenditure database that spent at least $\$ 10$ 000/year in 2016. Based on this, we added 1 cigarette, 10 e-cigarette and 2 cigar brands. Finally, we added 17 hookah brands listed by adult users who reported having a regular brand in wave 2 of the Population Assessment of Tobacco and Health Study. ${ }^{53}$ This process yielded a total of 130 brands for the search: 19 cigarette, 20 smokeless tobacco, 30 e-cigarette, 18 hookah and 43 cigar brands.

We used an Android and an Apple smartphone to search for consumer-oriented mobile websites representing each of the brands using Google on Safari (Apple) or Chrome (Android) browsers. In November 2017, we searched for each brand and product category name (eg, Camel cigarettes) and reviewed the first page of results. We excluded websites that: (1) did not appear smartphone-optimised (ie, required zooming in or scrolling left to right to view) or (2) did not appear to be consumer-oriented (eg, appeared aimed at investors). We identified 62 brand websites using this search strategy.

\section{Coding}

\section{Coding process}

We conducted an inductive content analysis, ${ }^{54}$ where we derived our coding scheme from the website characteristics we observed. Each page of each website was coded, and all websites were dualcoded to ensure that nothing was missed. First, all three investigators conducted practice coding on 10 websites. We had $87 \%$ agreement. After reconciling differences, we edited the coding scheme. Remaining websites were coded by two investigators. We had high agreement between each pair of raters (95\%-98\%) and met to resolve discrepancies. Below we describe the four features coded. We also recorded a text description of each feature we identified during coding.

\section{Youth access}

We coded whether each website required an age-verified account to enter and, if not, whether an age-verified account was required to purchase tobacco. When website entry required an account, investigators created an account using personal information. For websites not requiring accounts, we coded for mode of age verification (eg, click-through). We also coded whether websites sold tobacco products and branded merchandise (eg, t-shirts). For websites selling tobacco, we attempted tobacco product purchase to see if we were prompted to create an account to check out.

\section{Health warnings}

We coded two aspects of health warnings: presence and visibility. We coded whether warnings were present at all, on the landing page only, on all pages or only viewed by clicking on a link. We coded the visibility of the warning and what the user had to do 
Table 1 Age requirements to enter and purchase from tobacco brand mobile websites

\begin{tabular}{|c|c|c|c|c|c|}
\hline & Cigarette & Smokeless tobacco & E-cigarettes & Hookah & Cigar \\
\hline & $n=10$ & $n=9$ & $\mathrm{n}=21$ & $n=5$ & $n=17$ \\
\hline & $\%(n)$ & $\%(n)$ & $\%(n)$ & $\%(n)$ & $\%(n)$ \\
\hline \multicolumn{6}{|l|}{ Site entry requirements } \\
\hline Age-verified account required & $100(10)$ & $89(8)$ & 0 & 0 & $24(4)$ \\
\hline No account required & 0 & $11(1)$ & $100(21)$ & $100(5)$ & $76(13)$ \\
\hline Click-through-18+ & 0 & 0 & $33(7)$ & 0 & 0 \\
\hline Click-through-21+ & 0 & 0 & $43(9)$ & 0 & $54(7)$ \\
\hline Enter birth date & 0 & $100(1)$ & $5(1)$ & 0 & $23(3)$ \\
\hline Birth date and $21+$ click & 0 & 0 & 0 & 0 & $8(1)$ \\
\hline Birth date and state legal age & 0 & 0 & 5 & 0 & 0 \\
\hline No age verification & 0 & 0 & $14(3)$ & $100(5)$ & $12(2)$ \\
\hline \multicolumn{6}{|l|}{ Online purchasing } \\
\hline Sells tobacco & 0 & 0 & $95(20)$ & $80(4)$ & $6(1)$ \\
\hline $\begin{array}{l}\text { Can order with no account but has option for account for } \\
\text { easier checkout or coupons }\end{array}$ & 0 & 0 & $25(5)$ & $50(2)$ & 0 \\
\hline Order requires account with age verification & 0 & 0 & $75(15)$ & $50(2)$ & $100(1)$ \\
\hline Sells branded merchandise & 0 & 0 & $43(9)$ & $80(4)$ & 0 \\
\hline
\end{tabular}

Italic rows represent percentages of a subcategory.

to see it-scroll up, scroll down with one scrolling motion, scroll down with multiple scrolling motions or no scrolling. We did not code warning content.

\section{Brand engagement}

We coded whether websites offered different opportunities to engage consumers with brands: games, prizes, sweepstakes, internal social media (ie, an opportunity for users to interact) and links to external social media platforms. We coded whether videos were embedded in the website and whether these videos featured brand identity themes (ie, highlighted the values or activities of typical product users), described product attributes (eg, e-cigarette battery life) and described how to use the product. These codes were not mutually exclusive.

\section{Purchase facilitation}

We coded product description presence, whether users could leave product reviews, presence of store locators and whether geolocation was automated, whether live chat support was offered and whether customers could enrol in a points system to receive discounts or prizes. We coded several elements of brickand-mortar store coupons: whether they were offered, whether they were described as regularly offered, whether the website offered a choice of coupons and whether coupons used geolocation and a time limit. We also coded whether other discounts were offered (eg, free shipping, discount codes).

\section{RESULTS}

Most e-cigarette brands (21/30) had mobile websites for consumers, while few hookah brands did (5/18). Approximately half of cigarette (10/19), smokeless tobacco (9/20) and cigar (17/43) brands had mobile websites. Results are presented in tables 1-4; below we summarise them and provide detailed examples.

\section{Age requirements}

All age-verified accounts required name and birth date; most websites verified age using a third-party service that requested the last four digits of the social security number, driver's licence number or previous address to confirm identity. All cigarette

Table 2 Product warning presence and visibility on tobacco brand mobile websites

\begin{tabular}{|c|c|c|c|c|c|}
\hline & Cigarette & Smokeless tobacco & E-cigarettes & Hookah & Cigar \\
\hline & $n=10$ & $n=9$ & $\mathrm{n}=21$ & $n=5$ & $\mathrm{n}=17$ \\
\hline & $\%(n)$ & $\%(n)$ & $\%(n)$ & $\%(n)$ & $\%(n)$ \\
\hline \multicolumn{6}{|l|}{ Warning presence } \\
\hline No warning present & 0 & 0 & $33(7)$ & $100(5)$ & $24(4)$ \\
\hline Present on landing page & 0 & 0 & $10(2)$ & 0 & 0 \\
\hline Present on all pages & $100(10)$ & $100(9)$ & $52(11)$ & 0 & $76(13)$ \\
\hline Link to warning & 0 & 0 & $5(1)$ & 0 & 0 \\
\hline \multicolumn{6}{|l|}{ Warning visibility } \\
\hline No warning & 0 & 0 & $33(7)$ & $100(5)$ & $24(4)$ \\
\hline Required scrolling up & $50(5)$ & $44(4)$ & $10(2)$ & 0 & $24(4)$ \\
\hline Required extensive scrolling down & $40(4)$ & 0 & $48(10)$ & 0 & $24(4)$ \\
\hline Required one scroll down & 0 & 0 & $5(1)$ & 0 & $18(3)$ \\
\hline Required no scrolling & $10(1)$ & $56(5)$ & $5(1)$ & 0 & $12(2)$ \\
\hline
\end{tabular}


Table 3 Brand engagement features present in tobacco brand mobile websites: email sign-up, advertising app, entertainment features, prizes and social features

\begin{tabular}{|c|c|c|c|c|c|}
\hline & Cigarette & Smokeless tobacco & E-cigarettes & Hookah & Cigar \\
\hline & $n=10$ & $n=9$ & $\mathrm{n}=21$ & $n=5$ & $n=17$ \\
\hline & $\%(\mathrm{n})$ & $\%(\mathbf{n})$ & $\%(n)$ & $\%(n)$ & $\%(n)$ \\
\hline Sign-up for emails or text messages & $90(9)$ & $89(8)$ & $81(17)$ & $80(4)$ & $71(12)$ \\
\hline Advertises brand's app & $10(1)$ & $22(2)$ & $5(1)$ & 0 & 0 \\
\hline \multicolumn{6}{|l|}{ Entertainment* ${ }^{*}$} \\
\hline Videos & $60(6)$ & $44(4)$ & $43(9)$ & $20(1)$ & $35(6)$ \\
\hline Brand identity & $83(5)$ & $100(4)$ & $22(2)$ & $100(1)$ & $50(3)$ \\
\hline How product is made & $33(2)$ & $25(1)$ & 0 & 0 & $33(2)$ \\
\hline Describes product attributes & $67(4)$ & 0 & $100(9)$ & $100(1)$ & $17(1)$ \\
\hline How to use & 0 & $25(1)$ & $56(5)$ & $100(1)$ & 0 \\
\hline Games & $30(3)$ & $11(1)$ & 0 & 0 & $12(2)$ \\
\hline \multicolumn{6}{|l|}{ Prize winning } \\
\hline Specific prizes described & $60(6)$ & $78(7)$ & $10(2)$ & $20(1)$ & $18(3)$ \\
\hline Sweepstakes & $70(7)$ & $67(6)$ & $19(4)$ & 0 & $53(9)$ \\
\hline Active & $14(1)$ & $67(4)$ & $25(1)$ & 0 & $11(1)$ \\
\hline In past, or in Terms Of Service & $86(6)$ & $33(2)$ & $75(3)$ & 0 & $89(8)$ \\
\hline Internal social features* & $60(6)$ & $44(4)$ & $14(3)$ & 0 & $12(2)$ \\
\hline External social media† & 0 & $11(1)$ & $67(14)$ & $100(5)$ & $59(10)$ \\
\hline Facebook & 0 & $100(1)$ & $100(14)$ & $100(5)$ & $80(8)$ \\
\hline Twitter & 0 & 0 & $100(14)$ & $80(4)$ & $80(8)$ \\
\hline Instagram & 0 & 0 & $64(9)$ & $80(4)$ & $60(6)$ \\
\hline Pinterest & 0 & 0 & $50(7)$ & $60(3)$ & $30(3)$ \\
\hline Other social media $\ddagger$ & 0 & 0 & $79(11)$ & $80(4)$ & $70(7)$ \\
\hline
\end{tabular}

Italic rows represent percentages of a subcategory.

*Such as topic discussion forums, image sharing platforms and comments on content, internal to the brand's website.

tSubcategories are not mutually exclusive.

¥Such as Google Plus, Linkedln and YouTube.

websites required an age-verified account for entry, as did most smokeless tobacco websites, no hookah, no e-cigarette and one-quarter of cigar websites (table 1).

Websites not requiring accounts used a variety of other age verification strategies. E-cigarette websites commonly used a pop-up window that required users to click a button asserting they were at least 18 or 21 years old. Several websites required users to enter their birth date.

Several e-cigarette and cigar and all hookah websites did not have any age verification for website entry. Most e-cigarette and hookah websites sold tobacco products and accessories (eg, batteries, coals). A quarter of e-cigarette and half of hookah

Table 4 Purchase facilitation features present on tobacco brand mobile websites: product description, coupons, store locators and other features

\begin{tabular}{|c|c|c|c|c|c|}
\hline & Cigarette & Smokeless tobacco & E-cigarettes & Hookah & Cigar \\
\hline & $\mathrm{n}=10$ & $n=9$ & $\mathrm{n}=21$ & $n=5$ & $n=17$ \\
\hline & $\%(n)$ & $\%(n)$ & $\%(n)$ & $\%(n)$ & $\%(n)$ \\
\hline Product image and description & $100(10)$ & $100(9)$ & $100(21)$ & $100(5)$ & 100 (17) \\
\hline Description of taste & $70(7)$ & $67(6)$ & $38(8)$ & $40(2)$ & $82(14)$ \\
\hline Offers coupons* & $100(10)$ & $89(8)$ & $38(8)$ & 0 & $18(3)$ \\
\hline Described as regularly offered & $90(9)$ & $50(4)$ & $13(1)$ & 0 & 0 \\
\hline Offers choice of coupon & $70(7)$ & 50 (4) & $25(2)$ & 0 & 0 \\
\hline Uses geolocation and time limit & $50(5)$ & $38(3)$ & 0 & 0 & 0 \\
\hline Offers other discounts $t$ & $10(1)$ & 0 & $57(12)$ & $80(4)$ & 0 \\
\hline Store locator & $40(4)$ & $78(7)$ & $62(13)$ & $20(1)$ & $59(10)$ \\
\hline Used geolocation data & 75 (3) & $86(6)$ & $62(8)$ & 0 & $10(1)$ \\
\hline \multicolumn{6}{|l|}{ Other features } \\
\hline Reviews & 0 & 0 & $52(11)$ & $20(1)$ & $6(1)$ \\
\hline Points system & 0 & 0 & $38(8)$ & $20(1)$ & $6(1)$ \\
\hline Live chat support & 0 & 0 & $29(6)$ & $20(1)$ & 0 \\
\hline
\end{tabular}

Italic rows represent percentages of a subcategory.

*Subcategories are not mutually exclusive.

†Such as free shipping, free products with purchase of a certain quantity, sale items. 
websites selling tobacco did not require an age-verified account for checkout though most offered optional accounts for faster checkout. Approximately half of e-cigarette and most hookah websites sold branded merchandise such as t-shirts, carrying cases and hats.

\section{Health warnings}

All cigarette and smokeless tobacco websites displayed required warnings on each page of the website. Half of cigarette and almost half of smokeless tobacco websites required the user to scroll $u p$ above the menu to view the warning. Almost half of cigarette websites required extensive scrolling down to view the warning, whereas no scrolling was required to see warnings on more than half of smokeless tobacco websites. Many websites also displayed warnings while pages were loading (table 2).

Warnings were absent on one-third of e-cigarette, all hookah and one-quarter of cigar mobile websites. Some e-cigarette mobile websites only displayed a warning on the landing page, and approximately half required extensive scrolling down to view warnings. The types of warnings displayed on e-cigarette websites varied. Some were about the addictiveness of nicotine, some were California Proposition 65 warnings (related to reproductive harm) and some provided lists of medical conditions that precluded product use. Cigar websites varied in the amount of scrolling required to see warnings and appeared to display warnings that would be required in August 2018. ${ }^{25}$

\section{Brand engagement}

Websites used a variety of brand engagement methods. Almost all websites offered consumers the option to sign up for promotional emails, and some also offered the option to receive text messages. One cigarette website, two smokeless tobacco websites and one e-cigarette website advertised brand-sponsored apps that people could download to access coupons (table 3).

Approximately half of cigarette, smokeless tobacco and e-cigarette websites offered videos, as did one-fifth of hookah and about one-third of cigar websites. Video themes varied by product category. Most cigarette, all smokeless tobaccos and half of cigar videos were focused on brand identity, showcasing user values and activities. For example, Copenhagen smokeless tobacco offered videos of men doing stereotypically masculine blue-collar jobs, such as building boats and repairing engines. All e-cigarette videos highlighted product attributes, and half showed viewers how to use the product. About one-quarter to one-third of cigarette, smokeless tobacco and cigar videos showed how their product was made, while no e-cigarette or hookah videos did so.

Few websites offered games. Some websites had instant win card games (Kool and Winston cigarettes) and hunting and fishing games (Copenhagen smokeless tobacco and Punch cigars). Marlboro had three games, including poker, a matching game and a Marlboro country virtual trip game. Al Capone cigars had a trivia game to win branded merchandise.

While more than half of cigarette and smokeless tobacco websites described prizes, few websites of other product categories did. Most cigarette, smokeless tobacco and cigar website terms of service mentioned sweepstakes, but only one cigarette website and one cigar website had an active sweepstakes. Smokeless websites were most likely to have an active sweepstakes. Prizes included trips to car races and the Grand Canyon, discounts, tobacco products and branded merchandise.

Social media features varied by product type-e-cigarette, hookah and cigar websites tended to link to social media platforms rather than hosting socialising opportunities, while cigarettes and smokeless tobacco tended not to be linked to external social media platforms and hosted socialising opportunities. Among e-cigarette, hookah and cigar websites, the most commonly linked social media platforms were Facebook and Twitter, followed by Instagram and Pinterest. Many websites also linked to other platforms, including GooglePlus, LinkedIn and YouTube.

Approximately half of cigarette and smokeless tobacco websites offered internal social media platforms. They offered different formats to connect with other users, including having people respond to questions, vote on preferences and share images. Newport, Pall Mall, Marlboro, Virginia Slims, L\&M and Skoal allowed people to respond to a posted question, such as what their best bad joke is, how to turn trash into treasure, how to have fun without spending too much money, unusual methods to catch fish or what makes you proud of your home town. Copenhagen allowed people to share photos of barbecued meat in an Instagram-like format, and Grizzly let people vote on a variety of stereotypically masculine issues, such as 'zero turn mower vs classic riding mower'. Several websites allowed people to create content that could be used in labelling or advertising. For example, Grizzly let people finish proposed ads, for example, 'Fishing is a sport, not (fill in the blank).' All platforms allowed users to leave comments and like others' posts.

\section{Purchase facilitation}

All websites included specific product images and descriptions. Most described the taste of flavoured and unflavoured products. Most smokeless tobacco and approximately half of cigarette, e-cigarette and cigar websites featured store locators. Most smokeless tobacco and e-cigarette store locators used geolocation data to automatically display nearby stores (table 4).

E-cigarette websites offered several unique strategies: about half offered users opportunities to leave reviews of specific products, usually a star rating and narrative text; more than one-third offered reward points systems to earn discounts on future purchases; and more than a quarter offered live chat support. Additionally, Blu e-cigarettes offered points for connecting with the brand on social media.

Coupons were offered on all cigarette and most smokeless tobacco websites, some e-cigarette and cigar websites, and no hookah websites. They could be loaded on a smartphone and scanned at a store. Most cigarette and half of smokeless tobacco coupons were described as offered regularly (eg, weekly or monthly) and offered users a choice of coupons, typically a smaller amount (eg, \$1) off a single unit or can or a larger amount (eg, \$3) off multiple units (eg, carton or roll).

Half of cigarette coupons and more than one-third of smokeless tobacco coupons were location-based, time-sensitive coupons. Consumers could select their coupon and their store, activate the coupon when inside the store (confirmed by geolocation data) and checkout with the coupon within 5 min of activation. Many e-cigarette and hookah mobile websites offered discounts such as free shipping and free products with purchases of certain quantities. For example, Mistic e-cigarettes offered $50 \%$ off on a starter kit, GreenSmartLiving e-cigarettes offered a $20 \%$ discount on recycling 50 used cartridges and batteries, and Juul e-cigarettes offered $15 \%$ off on autoshipment subscriptions.

\section{DISCUSSION}

This study described features of mobile websites for leading tobacco brands. Because people increasingly access the internet via smartphone, ${ }^{5}$ it is important to understand mobile websites, 
particularly because they may differ from regular websites. ${ }^{11}{ }^{12} \mathrm{We}$ found that most leading e-cigarette brands had mobile websites, as did about half of leading cigarette, smokeless tobacco and cigar brands, but few hookah tobacco brands. This study adds to the literature by shedding light on the methods that tobacco companies use to restrict youth access, display warnings, engage viewers and facilitate purchase on mobile websites.

Age verification requirements for entering tobacco websites can help prevent youth from accessing tobacco marketing content which could reduce youth tobacco use. ${ }^{13}{ }^{14}$ Cigarette and smokeless tobacco websites required users to register for an account and used third parties to verify age and identity. Most e-cigarette, hookah and cigar mobile websites did not require accounts, many did not verify age before entering and those who did were limited to click throughs. This finding is consistent with studies of e-cigarette brand ${ }^{1619}$ and vendor ${ }^{151718}$ websites. Additionally, several e-cigarette websites and all hookah websites selling tobacco products did not require age-verified accounts to check out. Similarly, a 2014 study found youth could complete a purchase of e-cigarettes on many websites without age verification. ${ }^{55}$ As most youth own smartphones ${ }^{10}$ and often use them without parental supervision, ${ }^{56}$ these findings indicate a potential for youth to purchase e-cigarettes and hookah tobacco online. Indeed, FDA has sent warning letters to online e-cigarettes retailers selling to minors. ${ }^{57}$

Research finds that health warnings can prevent tobacco initiation and encourage cessation. ${ }^{20}$ Several federal laws require warnings to be displayed on packaging and advertising for tobacco products sold or distributed in the USA. ${ }^{21-26}$ On 10 August 2018, a law will require warnings for other tobacco products, including e-cigarettes and hookah. ${ }^{26}$ Although the law also requires warnings for cigars (and pipe tobacco), ${ }^{25}$ the US District Court for the District of Columbia issued an order enjoining FDA from enforcing this requirement for these products until after a related court case is settled. ${ }^{27}$ Although it is encouraging that cigarette and smokeless tobacco websites studied all displayed required warnings, many were not readily visible (eg, posted them above the menu, requiring consumers to scroll up). While many e-cigarette, hookah and cigar websites did not display any warnings, this could change when the aforementioned warning requirements are implemented. ${ }^{2526}$

All tobacco websites offered multiple brand engagement opportunities, and some were similar across websites. Almost all offered consumers the option to sign up for promotional emails which have content linking back to brand websites. ${ }^{30} 37$ Many websites also offered videos; cigarette and smokeless tobacco videos centred on brand identity which could foster brand loyalty. ${ }^{58}$ Consistent with a past study, ${ }^{59}$ e-cigarette videos served informational purposes, teaching users how to use the product and highlighting product attributes. While previous studies found tobacco companies commonly offered games and sweepstakes, ${ }^{384460}$ we found few mobile websites actively did.

Nearly all e-cigarette and hookah websites and about half of cigar websites were linked to external social media, primarily Facebook, Twitter, Instagram and Pinterest. In addition to increasing brand liking and loyalty, ${ }^{27}$ branded social media posts can drive traffic to websites. ${ }^{1936}$ This is concerning because most youth use social media, ${ }^{61}$ and e-cigarette social media posts can diffuse to non-users. ${ }^{62}$ Thus, youth could be directed via a social media post to a brand's website, where they could view content and potentially buy tobacco without age verification.

Almost no cigarette or smokeless tobacco websites were linked to social media. This could be because many of these companies agreed to the 1998 Master Settlement Agreement ${ }^{63}$ that restricts marketing to youth (social media is used by most youth). ${ }^{59}$ Instead of external social media, websites for these product types offered internal interaction opportunities. This is consistent with a study ${ }^{19}$ that found that cigarette websites were more likely to offer interactive features, while cigar and e-cigarette websites were more likely to link to external social media. By offering online socialisation opportunities, tobacco brands could be creating an environment for users to interact with one another without fear of rejection for tobacco use. This could be creating an 'echo chamber' ${ }^{\text {'64 }}$ that could normalise tobacco use and reduce quit motivation. Given these findings, tobacco education interventions could consider establishing a strong social media presence and offer socialisation opportunities for people trying to avoid tobacco use.

Tobacco companies used a variety of strategies to encourage product purchase, some of which were common across websites. Most mobile websites offered store locators, and many store locators capitalised on smartphone technology by using geolocation data to automatically populate the list of nearby retailers. This could reduce a barrier to tobacco purchase.

For all product websites except for cigars, consumers were provided with money-saving opportunities. Consistent with past research, ${ }^{193744} 45$ we found that brick and mortar store coupons were offered on all cigarette and almost all smokeless tobacco mobile websites, and they were offered on a regular basis. Consistent with marketing research recommendations, ${ }^{48} 49$ many coupons were time-sensitive and could only be activated when geolocation data confirmed the customer's in-store presence. This is concerning, given that exposure to coupons is associated with increased intentions to purchase cigarettes among youth smokers ${ }^{65}$ and decreased quitting among adult smokers. ${ }^{46}$

Consistent with previous research, ${ }^{15} 39$ we found that nearly all e-cigarette and hookah mobile websites sold tobacco products. They offered other discounts (eg, free shipping) rather than coupons, possibly increasing purchase rates. ${ }^{42}$ E-cigarette websites used multiple strategies identified in the marketing literature as effective ways to facilitate product purchase: customer reviews, live chat, points programmes and free products. ${ }^{41-4366}$ Overall, our results suggest that tobacco mobile websites use strategies to facilitate product purchase that are consistent with recommended marketing practices. As these strategies could re-engage people trying to quit tobacco, cessation efforts could be improved by addressing them.

Overall, we found that cigarette and smokeless tobacco websites generally tended to be more conservative than cigar, e-cigarette and hookah websites in that they had more age verification requirements, more often displayed health warnings, almost never linked to external social media and almost never sold tobacco online. One explanation for this pattern of findings could be that cigarettes and smokeless tobacco have been regulated by FDA for a longer period of time than the other products. Cigarettes and smokeless tobacco were brought under FDA's authority by the 2009 Family Smoking Prevention and Tobacco Control Act (FSPTCA). ${ }^{67}$ Among other things, the FSPTCA restricted marketing and sales to children and changed some tobacco health warning requirements. It was not until 2016 that FDA issued a rule ${ }^{68}$ that deemed cigars, e-cigarettes and hookah tobacco (and other products meeting the definition of a tobacco product) to be under FDA's regulatory authority, and portions of this rule have yet to take effect. 


\section{Strengths and limitations}

Study strengths include examining five tobacco product classes, the inductive coding approach that captured a range of characteristics and the dual coding of all results. The main limitation is that this study only provides a snapshot in time. This study was limited in that we did not code all website features (eg, events). Finally, this study is limited by the exclusion of non-US, non-English websites. However, these results could still inform non-US audiences, as tobacco companies use similar strategies across different countries, ${ }^{69}$ and smartphone ownership is growing worldwide. $^{70}$

Future research could update and build on these results to keep public health researchers and practitioners abreast of the tobacco marketing landscape. Future research could: (1) update results to account for changes in smartphone technology and the popularity of various tobacco products, brands and social media platforms; (2) code additional features and could code more specific themes present in videos and internal social media and (3) replicate this study in other countries, and compare and contrast the mobile website strategies tobacco companies are taking across the globe.

\section{CONCLUSION}

About half of leading tobacco brands have smartphone-optimised websites. Cigarette and smokeless tobacco websites use more rigorous methods to prevent youth access and better displayed warnings compared with e-cigarette, hookah and cigar websites. Websites offered brand engagement options including videos, sign-up for promotional emails and socialisation opportunities. Cigarette and smokeless tobacco websites offered location-based time-sensitive coupons, while most e-cigarette and

\section{What this paper adds}

- Data show that tobacco company expenditure on website development is increasing; smartphone ownership and use for internet access is also increasing in several tobaccosusceptible populations.

- Past descriptive research on regular tobacco websites has largely been limited to e-cigarette websites; no past research describes how tobacco companies are engaging smartphone users with mobile-optimised web content.

- This study describes how age is verified for website entry and for tobacco purchase, how health warnings are displayed, common brand engagement methods and common purchase facilitation strategies for 62 mobile websites for leading brands of cigarettes, smokeless tobacco, e-cigarette and hookah.

- We found that cigarette and smokeless tobacco mobile websites restricted age and displayed warnings more frequently than websites for other product types.

- Cigarette and smokeless tobacco mobile websites facilitated socialisation between users internally, while mobile websites for other products were linked to external social media platforms.

- Most websites offered coupons or other discounts, and many cigarette and smokeless tobacco websites offered timesensitive coupons that could only be activated inside a store.

- Results can help public health educators and practitioners understand the tobacco marketing landscape as a context for designing tobacco interventions, and may inform specific intervention strategies. hookah websites offered other discounts. These results can inform tobacco intervention strategies, such as providing online socialisation opportunities for people trying to avoid tobacco use, and addressing how tobacco websites might re-engage people trying to quit.

Contributors EKO'B designed and planned the research with input from MAN and LH. All authors developed the coding scheme and coded the results. EKO'B conducted analyses and led the drafting of the manuscript in collaboration with MAN and LH.

Funding The authors have not declared a specific grant for this research from any funding agency in the public, commercial or not-for-profit sectors.

Disclaimer This publication represents the views of the authors and does not represent FDA/CTP position or policy.

Competing interests None declared.

Patient consent Not required.

Provenance and peer review Not commissioned; externally peer reviewed.

\section{REFERENCES}

1 Federal Trade Commission. Federal trade commission cigarette report for 2015. 2017 https://www.ftc.gov/system/files/documents/reports/federal-trade-commissioncigarette-report-2015-federal-trade-commission-smokeless-tobacco-report/2015_ cigarette_report.pdf (accessed 18 Apr 2018).

2 Federal Trade Commission. Federal trade commission smokeless tobacco report for 2015. 2017 https://www.ftc.gov/system/files/documents/reports/federal-tradecommission-cigarette-report-2015-federal-trade-commission-smokeless-tobaccoreport/2015_smokeless_tobacco_report.pdf (accessed 18 April 2018).

3 Smith A. Smartphone ownership—2013 update. Washington, DC: Pew Research Center, 2013.

4 Insights N. Millennials are top smartphone users. New York, NY: Nielsen, 2016.

5 eMarketer. Growth of time spent on mobile devices slows. New York, NY: eMarketer, 2015.

6 Jamal A, Homa DM, O'Connor E, et al. Current cigarette smoking among adults United States, 2005-2014. MMWR Morb Mortal Wkly Rep 2015;64:1233-40.

7 Seidenberg $A B$, Jo CL, Ribisl KM, et al. A national study of social media, television, radio, and internet usage of adults by sexual orientation and smoking status: implications for campaign design. Int J Environ Res Public Health 2017;14:450.

8 Rainie L, Perrin A. 10 facts about smartphones as the iPhone turns 10. Washington, DC: Pew Research Center, 2017.

9 Heffner JL, Mull KE. Smartphone ownership among US adult cigarette smokers: 2014 Health Information National Trends Survey (HINTS) data. J Med Internet Res 2017; 19:e305

10 Lenhart A. A majority of American teens report having access to a computer, game console, smartphone, and tablet. Washington, DC: Pew Research Center, 2015.

11 Maurer ME, Hausen D, De Luca A, et al. Mobile or desktop websites?: website usage on multitouch devices. Presented at the 6th Nordic Conference on Human-Computer Interaction: extending boundaries, Reykjavik, Iceland. https://www.researchgate. net/profile/Doris_Hausen/publication/221248334_Mobile_or_Desktop_Websites_ Website_Usage_on_Multitouch_Devices/links/09e41508100fe3b6a4000000.pdf (accessed 18 Apr 2018)

12 Schneider R, McCown F. First steps in archiving the mobile web: automated discovery of mobile websites. Presented at the 13th ACM/IEEE-CS joint conference on digital libraries, Indianapolis, IN. https://www.harding.edu/fmccown/pubs/jcdlsp182schneider.pdf (accessed 18 Apr 2018).

13 Soneji S, Pierce JP, Choi K, et al. Engagement with online tobacco marketing and associations with tobacco product use among U.S. youth. J Adolesc Health 2017;61:61-9.

14 Soneji S, Yang J, Knutzen KE, et al. Online tobacco marketing and subsequent tobacco use. Pediatrics 2018;141:e20172927-11.

15 Williams RS, Derrick J, Liebman AK, et al. Content analysis of age verification, purchase and delivery methods of internet e-cigarette vendors, 2013 and 2014. Tob Control 2018;27:287-93.

16 Soneji S, Gerling M, Yang J, et al. Online electronic cigarette marketing-violation of self-regulated standards by tobacco companies. JAMA Pediatr 2016;170:511-2.

17 Grana RA, Ling PM. "Smoking revolution": a content analysis of electronic cigarette retail websites. Am J Prev Med 2014;46:395-405.

18 Mackey TK, Miner A, Cuomo RE. Exploring the e-cigarette e-commerce marketplace: Identifying Internet e-cigarette marketing characteristics and regulatory gaps. Drug Alcohol Depend 2015;156:97-103.

19 Escobedo P, Cruz TB, Tsai KY, et al. Monitoring tobacco brand websites to understand marketing strategies aimed at tobacco product users and potential users. Nicotine Tob Res 2017 
20 Hammond D. Health warning messages on tobacco products: a review. Tob Control 2011;20:327-37.

21 Federal Trade Commission. The federal cigarette labeling and advertising Act 15. Washington, DC: Federal Trade Commission.

22 Section 201 of the Tobacco Control Act. Cigarette labels and advertising warnings. Silver Spring, MD: Food and Drug Administration.

23 Section 204 of the Tobacco Control Act. Smokeless Tobacco Labels and Advertising Warnings. Silver Spring, MD: Food and Drug Administration.

24 Federal Trade Commission. Comprehensive smokeless tobacco health education act of 1986. Washington, DC: Federal Trade Commission.

25 Code of Federal Regulations. Title 21 - Food and Drugs; Chapter I - Food and Drug Administration Department of Health and Human Services; Subchapter K - Tobacco Products; Part 1143 - Minimum Required Warning Statements; Sec. 1143.5 Required warning statements for cigars (21CFR1143.5). Silver Spring, MD: Food and Drug Administration.

26 US Department of Health and Human Services, Food and Drug Administration. Title 21 - Food and Drugs; Chapter I - Food and Drug Administration Department of Health and Human Services; Subchapter K - Tobacco Products; Part 1143 Minimum Required Warning Statements; Sec. 1143.3 Required warning statements regarding addictiveness of nicotine (21CFR1143.3). Silver Spring, MD: Food and Drug Administration.

27 US Department of Health and Human Services, Food and Drug Administration. Cigar labeling and warning statement requirements. 2018. https://www.fda.gov/ tobaccoproducts/labeling/labeling/ucm524442.htm (accessed 2 Aug 2018).

28 Ashley C, Tuten T. Creative strategies in social media marketing: an exploratory study of branded social content and consumer engagement. Psychol Mark 2015;32:15-27.

29 Chi HK, Yeh HR, Yang YT. The impact of brand awareness on consumer purchase intention: The mediating effect of perceived quality and brand loyalty. J Int Manag Stud 2009;4:135-44.

30 Martin K, Todorov I. How will digital platforms be harnessed in 2010, and how will they change the way people interact with brands? Journal of Interactive Advertising 2010:10:61-6.

31 Brock B, Carlson SC, Moilanen M, et al. Reaching consumers: How the tobacco industry uses email marketing. Prev Med Rep 2016;4:103-6.

32 Cantrell J, Ganz O, Emelle B, et al. Mobile marketing: an emerging strategy to promote electronic nicotine delivery systems. Tob Control 2017;26(e2):e1-e3.

33 Elkin L, Thomson G, Wilson N. Connecting world youth with tobacco brands: YouTube and the internet policy vacuum on Web 2.0. Tob Control 2010;19:361-6.

34 Freeman B, Chapman S. Open source marketing: camel cigarette brand marketing in the "Web 2.0" world. Tob Control 2009;18:212-7.

35 Ilakkuvan V, Cantrell J, Vallone D. 'Action. Adventure. Special offers.': how marlboro engages consumers on its website. Tob Control 2014;23:455-6.

36 Wackowski OA, Lewis MJ, Delnevo CD. Qualitative analysis of camel snus' website message board--users' product perceptions, insights and online interactions. Tob Control 2011;20:e1-5.

37 Liang $\mathrm{Y}$, Zheng $\mathrm{X}$, Zeng DD, et al. Exploring how the tobacco industry presents and promotes itself in social media. J Med Internet Res 2015;17:e24.

38 Ganz 0, Teplitskaya L, Cantrell J, et al. Direct-to-consumer marketing of cigar products in the United States. Nicotine Tob Res 2016;18:864-8.

39 Timberlake DS, Bruckner TA, Ngo V, et al. The reach and impact of direct marketing via brand websites of moist snuff. Tob Regul Sci 2016;2:153-65.

40 Morris DS, Fiala SC, Pawlak R. Opportunities for policy interventions to reduce youth hookah smoking in the United States. Prev Chronic Dis 2012;9:1-4.

41 Jo CL, Kornfield R, Kim Y, et al. Price-related promotions for tobacco products on twitter. Tob Control 2016;25:476-9.

42 Weinberg BD, Parise S, Guinan PJ. Multichannel marketing: Mindset and program development. Business Horizons 2007;50:385-94.

43 Lewis M, Singh V, Fay S. An empirical study of the impact of nonlinear shipping and handling fees on purchase incidence and expenditure decisions. Marketing Science 2006;25:51-64

44 Ho-Dac NN, Carson SJ, Moore WL. The effects of positive and negative online customer reviews: do brand strength and category maturity matter? J Mark 2013:77:37-53

45 Lewis MJ, Yulis SG, Delnevo C, et al. Tobacco industry direct marketing after the master settlement agreement. Health Promot Pract 2004;5(3 Suppl):75S-83.
46 Brock B, Schillo BA, Moilanen M. Tobacco industry marketing: an analysis of direct mail coupons and giveaways. Tob Control 2015;24:505-8.

47 Choi K, Hennrikus DJ, Forster JL, et al. Receipt and redemption of cigarette coupons, perceptions of cigarette companies and smoking cessation. Tob Control 2013;22:418-22

48 Seidenberg AB, Jo CL. Cigarette couponing goes mobile. Tob Control 2017;26:233-4.

49 Danaher PJ, Smith MS, Ranasinghe K, et al. Where, when, and how long: factors that influence the redemption of mobile phone coupons. J Marketing Res 2015;52:710-25.

50 Goic M, Guajardo J. Mobile technology and social media in retail: decomposing the value of geolocation information. Rochester, NY: SSRN 2016 (accessed 18 Apr 2018).

51 Dou W, Krishnamurthy S. Using brand websites to build brands online: a product versus service brand comparison. J Advert Res 2007;47:193-206.

52 Lewis MJ, Wackowski O. Dealing with an innovative industry: a look at flavored cigarettes promoted by mainstream brands. Am J Public Health 2006;96:244-51.

53 United States Department of Health and Human Services. National Institutes of Health. National Institute on Drug Abuse, and United States Department of Health and Human Services. Food and Drug Administration. Center for Tobacco Products. Population Assessment of Tobacco and Health (PATH) Study [United States] Restricted-Use Files. Ann Arbor, MI: Inter-university Consortium for Political and Social Research [distributor], 2017.

54 Elo S, Kyngäs H. The qualitative content analysis process. J Adv Nurs 2008;62:107-15.

55 Williams RS, Derrick J, Ribisl km. Electronic cigarette sales to minors via the internet. JAMA Pediatr 2015;169:e1563-6.

56 Donahue EH, Haskins R, Nightingale M. Using the media to promote adolescent wellbeing. Washington, DC: Brookings, 2008.

57 U.S. Food and Drug Administration. First warning letters issued for illegal sales of e-cigarettes, e-liquids, and cigars. https://www.fda.gov/downloads/TobaccoProducts/ GuidanceComplianceRegulatoryInformation/Retail/UCM520813.pdf (accessed 2 May 2018).

58 Wheeler A. Designing brand identity: an essential guide for the whole branding team. Hoboken, NJ: John Wiley \& Sons, 2017.

59 Paek HJ, Kim S, Hove T, et al. Reduced harm or another gateway to smoking? source, message, and information characteristics of E-cigarette videos on YouTube. $J$ Health Commun 2014:19:545-60.

60 Sepe E, Ling PM, Glantz SA. Smooth moves: bar and nightclub tobacco promotions that target young adults. Am J Public Health 2002;92:414-9.

61 The Associated Press-NORC Center for Public Affairs Research. Issue brief: instagram and snapchat are most popular social networks for teens; black teens are most active on social media, messaging apps. Chicago, IL: AP-NORC, 2017.

62 Chu KH, Unger JB, Allem JP, et al. Diffusion of messages from an electronic cigarette brand to potential users through twitter. PLoS One 2015;10:e0145387-11.

63 U.S. Attorney General. Master settlement agreement. 1998. https://www. attorneygeneral.gov/wp-content/uploads/2018/01/msa.pdf (accessed 20 Apr 2018)

64 Allem JP, Escobedo P, Chu KH, et al. Campaigns and counter campaigns: reactions on Twitter to e-cigarette education. Tob Control 2017:26:226-9.

65 Choi K. The associations between exposure to tobacco coupons and predictors of smoking behaviours among US youth. Tob Control 2016;25:232-5.

66 Berman B. Developing an effective customer loyalty program. Calif Manage Rev 2006;49:123-48

67 US Department of Health and Human Services, Food and Drug Administration. Family smoking prevention and tobacco control act. 2009. http://www.fda.gov/ TobaccoProducts/Labeling/RulesRegulationsGuidance/ucm262084.htm (Accessed 20 July, 2018).

68 US Department of Health and Human Services, Food and Drug Administration. Deeming tobacco products to be subject to the federal food, drug, and cosmetic act, as amended by the family smoking prevention and tobacco control act. 2016. http:// www.fda.gov/TobaccoProducts/Labeling/RulesRegulationsGuidance/ucm394909.htm (Accessed 20 July, 2018).

69 Hafez N, Ling PM. How Philip Morris built Marlboro into a global brand for young adults: implications for international tobacco control. Tob Control 2005;14:262-71.

70 Poushter J. Smartphone ownership and internet usage continues to climb in emerging economies. Washington, DC: Pew Research Center, 2016. 